\title{
KẾT QUẢ KHẢO SÁT MộT SỐ CHỈ SỐ ÁP LỰC GAN BÀN CHÂN Ở NGƯỜI VIÊTT NAM TRỬ̛̉NG THÀNH
}

\author{
Phạm Thúy Hường ${ }^{1}$, Phạm Tuấn Phương ${ }^{1}$, Nguyễn Thị Phi Nga ${ }^{2}$ Đỗ Đình Tùng ${ }^{3}$
}

1. Bệnh viện Nội tiết Trung ương

DOI: $10.47122 / v j d e .2020 .41 .4$

2. Học viện Quân y; 3. Trường Đại học Y Hà Nội

\section{ABSTRACT \\ Survey results of some plantar pressure indicators in Vietnamese adults}

Plantar pressure measurement will provide very important details in diagnosing on foot diseases to help preventing from the injuries. Target of researching: Identify some indexes of plantar pressure in Vietnamese adults. Object and method of research: 40 Vietnamese adults over 18 years old (Male: $35 \%$ and Female: $65 \%$ ) in average age of 41.5 \pm 10.1 years old). Study result: 40 participants in research (BMI $21.1 \pm 2.16$ $\mathrm{kg} / \mathrm{m}^{2}$ ). To record on the right foot: Top pressure in the whole foot: $334.06 \pm 104.83$ $\mathrm{kpa}$; the highest is in area of big toe: $270.33 \pm$ $133.57 \mathrm{kpa}$ and the lowest in area of toes 3,4,5: $85.19 \pm 49.09 \mathrm{kpa}$. Maximum force of the whole foot: $520.42 \pm 77.27 \mathrm{kpa}$; the highest in area of heel: $291.91 \pm 63.71(\mathrm{~N})$; the lowest in area of toe 2: $21.7 \pm 9.05(\mathrm{~N})$. On the left foot: Top pressure of the whole foot: $316.43 \pm 282.14 \mathrm{kpa}$; the highest in area of big toe: $237.29 \pm 139.22 \mathrm{kpa}$; the lowest in area of toes $345: 96.73 \pm 50.14 \mathrm{kpa}$. Maximum force of the whole foot: $528.98 \pm$ $66.56(\mathrm{~N})$; the highest in area of heel: 287.19 $\pm 59.04(\mathrm{~N})$; the lowest in area of toe 2: 20.93 $\pm 8.79(\mathrm{~N})$. Conclusion: Normal plantar pressure differs in different positions on the same foot, but does not differ between left and right.

Keyword: Plantar pressure

Chịu trách nhiệm chính: Phạm Tuấn Phương

Ngày nhận bài: 15/8/2020

Ngày phản biện khoa học: 11/9/2020

Ngày duyệt bài: 10/10/2020

Email: bsphuong80@gmail.com

Điện thoại: 0983049996

\section{TÓM TẮT}

Đo áp lực gan bàn chân sẽ đưa ra các thông tin hữu ích trong chẩn đoán các bệnh lý bàn chân giúp phòng ngừa các thương tích. Mục tiêu nghiên cúu: Xác định một số chỉ số áp lực gan bàn chân ở người Việt Nam trưởng thành. Đối tượng và phương pháp nghiên cúu: 40 người Việt Nam sức khỏe bình thường trên 18 tuổi được lựa chọn vào nghiên cứu (14 nam chiếm $35 \%$; 26 nữ chiếm $65 \%$; có tuổi trung bình $41,5 \pm 10,1)$. Sử dụng máy đo áp lực gan bàn chân EMED A50. Kết quả nghiên cứu: 40 đối tượng tham gia nghiên cứu có $\mathrm{BMI} 21,1 \pm 2,16$. Ghi nhận: Ở bàn chân phải: Áp lực đỉnh ở toàn bộ bàn chân: $334,06 \pm 104,83 \mathrm{kpa}$; cao nhất là vùng ngón cái: $270,33 \pm 133,57 \mathrm{kpa}$ và thấp nhất vùng ngón 345: 85,19 \pm 49,09 kpa. Lực tối đa toàn bộ bàn chân: $520,42 \pm 77,27$ kpa cao nhất vùng gót chân $291,91 \pm 63,71(\mathrm{~N})$ thấp nhất vùng ngón $2: 21,7 \pm 9,05(\mathrm{~N})$. Ở bàn chân trái: Áp lực đỉnh toàn bộ bàn chân: $316,43 \pm$ $282,14 \mathrm{kpa}$; cao nhất vùng ngón cai: $237,29 \pm$ $139,22 \mathrm{kpa}$; thấp nhất vùng ngón $345: 96,73 \pm$ $50,14 \mathrm{kpa}$. Lực tối đa toàn bộ bàn chân: $528,98 \pm 66,56(\mathrm{~N})$; cao nhất vùng gót chân $287,19 \pm 59,04(\mathrm{~N})$ thấp nhất vùng ngón 2 : $20,93 \pm 8.79(\mathrm{~N})$. Kết luận: Áp lực gan bàn chân ở người bình thường phân bố khác nhau ở các vị trí khác nhau trên cùng 1 bàn chân, nhưng không có sự khác nhau giữa 2 bên bàn chân trái và bàn chân phải.

Tù khóa: Áp lực gan bàn chân

\section{1. ĐẶT VẤN ĐỀ}

Bàn chân là một bộ phân rất quan trọng trong quá trình vận động di chuyển, chịu ảnh hưởng của trọng lượng cở thể, dáng đi, các bệnh lý thần kinh ngoại biên, bệnh khớp, bệnh đái tháo đường... 
Lực hay cũng gọi là lực tiếp đất là tổng hoặc lực tác động lên bàn chân khi đứng trên một mặt phẳng. Trong khi đó áp lực được đo bằng tổng số lực cung cấp cho một đơn vị diện tích và được tính bằng cách chia tổng số lực cho số diện tích mà nó tác động lên[3]. Áp lực trung bình bàn chân có thể được tính bằng chia tổng số lực cho toàn bộ diện tích bàn chân. Tuy nhiên trên thực tế thì lực này sẽ phân bố không đồng đều trên toàn bộ diện tích bàn chân nhất là khi đi bộ.

Lòng bàn chân là bề mặt chính của sự tương tác giữa cơ thể với môi trường trong quá trình vận động. Áp lực gan bàn chân là áp lực được tạo ra giữa bàn chân và các bề mặt tiếp xúc trong các hoạt động vận động hàng ngày.

Để chẩn đoán các bất thường về chân ở giai đoạn sớm nhằm phòng chống thương tích, quản lý các yếu tố nguy cơ và nâng cao chất lượng cuộc sống, một cách tiếp cận kiểm tra chân được ứng dụng rộng rãi là đo áp lực gan bàn chân.

Thông tin thu được từ các biện pháp đo áp lực gan bàn chân là rất quan trọng, cung cấp các thông tin để chẩn đoán các bệnh lý của chân, thiết kế giày dép và phòng chống thương tích và các ứng dụng khác [4],[5].

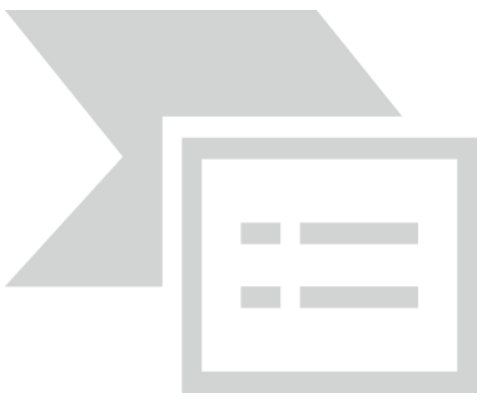

\section{2. ĐỐI TƯợNG VÀ PHƯƠNG PHÁP NGHIÊN CÚU}

Đối tượng và cõ̃ mẫu nghiên cứu: 40 người Việt Nam trưởng thành trên 18 tuổi có sức khỏe bình thường.

Tiêu chuẩn lựa chọn đối tượng nghiên cứu:

- Các đối tượng khỏe mạnh tuổi $\geq 18$ tuổi cả 2 giới nam và nữ.

- Đồng ý tham gia nghiên cứu.

- Có đầy đủ các thông tin cần thiết đáp ứng cho nghiên cứu.

Tiêu chuẩn lựa chọn đối tượng nghiên cứu:

- Các đối tượng mắc các bệnh cấp tính, mạn tính: shock, đột quy, liệt, tâm thần không hợp tác khi đo áp lực gan bàn chân...

- Đối tượng đái tháo đường, thừa cân, béo phì, phụ nữ có thai...

Các kỹ thuật dùng trong nghiên cứu:

- Phỏng vấn, hỏi tiền sử, khám lâm sàng; đo HA; đo chiều cao cân nặng; tính BMI.

- Xét nghiệm sinh hóa thường quy để loại trừ: Glucose máu; HbA1c; chức năng gan; chức năng thân; lipid máu.

- Sử dụng máy đo áp lực gan bàn chân của Emed $A 50$ đo 10 vùng tại bàn chân (các chỉ số đo: áp lực đỉnh, lực tối đa).

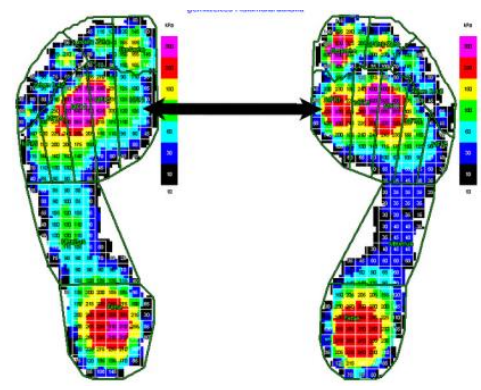

\section{KẾT QUẢ NGHIÊN CÚU}

Bảng 3.1.Phân bố đối tượng nghiên cứu theo nhóm tuổi và giới

\begin{tabular}{|c|c|c|}
\hline Nhóm tuổi & Số lượng $(\mathbf{n = 4 0 )}$ & Tỷ lệ (\%) \\
\hline $20-29$ & 6 & 15,0 \\
\hline $30-39$ & 13 & 32,5 \\
\hline $40-49$ & 9 & 22,5 \\
\hline $50-59$ & 12 & 30,0 \\
\hline Tuổi trung bình $(\mathrm{TB} \pm \mathrm{SD})$ & $\mathbf{4 1 , 5} \pm \mathbf{1 0 , 1}$ \\
\hline
\end{tabular}




\section{Giới tính}

\begin{tabular}{|c|c|c|}
\hline Nam & 26 & 65,0 \\
\hline Nữ & 14 & 35,0 \\
\hline
\end{tabular}

Các đối tượng nghiên cứu có tuổi trung bình 41,5 tuổi, thấp nhất 20 tuổi và cao nhất 59 tuổi, nhóm tuổi 30 - 39 tuổi chiếm tỷ lệ cao nhất.Các đối tượng nghiên cứu $65 \%$ là nữ và $35 \%$ là nam.

Bảng 3.2.Đặc điểm chỉ số nhân trắc của đối tượng nghiên cứu

\begin{tabular}{|l|c|}
\hline \multicolumn{1}{|c|}{ Chỉ số nhân trắc } & Nhóm chứng(n=40) \\
\hline Cân nặng $(\mathrm{kg})$ & $55,4 \pm 8,1$ \\
\hline Chiều cao $(\mathrm{m})$ & $1,62 \pm 0,07$ \\
\hline BMI $\left(\mathrm{kg} / \mathrm{m}^{2}\right)$ & $21,1 \pm 2,16$ \\
\hline
\end{tabular}

Các đối tượng tham gia nghiên cứu có chỉ số BMI trong giới hạn bình thường.

Bảng 3.3.Đặc điểm một số chỉ số sinh hóa của đối tượng nghiên cứu

\begin{tabular}{|l|c|}
\hline \multicolumn{1}{|c|}{ Chỉ số sinh hóa } & Nhóm chứng(n=40) \\
\hline Glucose $(\mathrm{mmol} / \mathrm{l})$ & $5,18 \pm 0,51$ \\
\hline HbAlc $(\%)$ & $5,26 \pm 0,74$ \\
\hline Cholesterol $(\mathrm{mmol} / \mathrm{l})$ & $4,77 \pm 0,57$ \\
\hline Triglycerid $(\mathrm{mmol} / \mathrm{l})$ & $1,35 \pm 0,35$ \\
\hline HDL-c $(\mathrm{mmol} / \mathrm{l})$ & $1,29 \pm 0,35$ \\
\hline LDL-c $(\mathrm{mmol} / \mathrm{l})$ & $2,87 \pm 0,54$ \\
\hline Ure $(\mathrm{mmol} / \mathrm{l})$ & $5,02 \pm 1,23$ \\
\hline Creatinin $(\mu \mathrm{mol} / \mathrm{l})$ & $70,75 \pm 12,65$ \\
\hline GOT $(\mathrm{UI} / \mathrm{l})$ & $23,08 \pm 10,35$ \\
\hline GPT $(\mathrm{UI} / \mathrm{l})$ & $23,57 \pm 9,74$ \\
\hline
\end{tabular}

- Các đối tượng nghiên cứu có chỉ số trong giới hạn bình thường.

- Không có đối tượng bị rối loạn lipid máu khi tham gia nghiên cứu.

Bảng 3.4. Đặc điểm lực tối đa bàn chân của đối tượng nghiên cứu

\begin{tabular}{|c|c|c|c|}
\hline Lụ̣c tối đa (N) & $\begin{array}{c}\text { Bàn chân phải } \\
(\mathrm{TB} \pm \mathrm{SD})(\mathrm{n}=40)\end{array}$ & $\begin{array}{c}\text { Bàn chân trái } \\
(T B \pm S D)(n=40)\end{array}$ & p value \\
\hline Tổng lực & $520.42 \pm 77.27$ & $528.98 \pm 66.56$ & \multirow{11}{*}{$\mathrm{p}>0,05$} \\
\hline Gót chân & $291.91 \pm 63.71$ & $287.19 \pm 59.04$ & \\
\hline Giữa chân & $117.68 \pm 43.18$ & $133.74 \pm 48.42$ & \\
\hline MH1 & $82.67 \pm 37.34$ & $80.88 \pm 27.41$ & \\
\hline MH2 & $102.22 \pm 42.36$ & $99.55 \pm 22.0$ & \\
\hline MH3 & $106.1 \pm 23.78$ & $107.76 \pm 22.93$ & \\
\hline MH4 & $67.0 \pm 22.13$ & $74.25 \pm 20.47$ & \\
\hline MH5 & $36.23 \pm 17.09$ & $37.72 \pm 11.68$ & \\
\hline Ngón cái & $95.44 \pm 38.94$ & $86.4 \pm 34.16$ & \\
\hline Ngón 2 & $21.7 \pm 9.05$ & $20.93 \pm 8.79$ & \\
\hline Ngón 3,4,5 & $29.05 \pm 40.45$ & $28.72 \pm 17.15$ & \\
\hline
\end{tabular}


* MH1: Nền xương ngón 1; MH2: Nền xương ngón 2; MH3: Nền xương ngón 3; MH4: Nền xương ngón 4; MH5: Nền xương ngón 5.

- Tổng lực tối đa bàn chân trái ở nhóm nghiên cứu cao hơn không có ý nghĩa thống kê với tổng lực ở bàn chân phải.

- Phân bố lực tối đa ở bàn chân không đều, cao nhất ở vùng gót chân và thấp nhất là lực vùng ngón 2.

Bảng 3.5. Đặc điểm áp lực đỉnh bàn chân của đối tượng nghiên cứu

\begin{tabular}{|c|c|c|c|}
\hline $\begin{array}{c}\text { Áp lực đỉnh } \\
\text { (kpa) }\end{array}$ & $\begin{array}{c}\text { Bàn chân phải } \\
(\mathrm{TB} \pm \mathrm{SD})(\mathrm{n}=40)\end{array}$ & $\begin{array}{c}\text { Bàn chân trái } \\
(\mathrm{TB} \pm \mathrm{SD})(\mathrm{n}=40)\end{array}$ & $p$ value \\
\hline Tổng lực & $334.06 \pm 104.83$ & $316.43 \pm 282.14$ & \multirow{11}{*}{$\mathrm{p}>0,05$} \\
\hline Gót chân & $185.62 \pm 40.04$ & $184.86 \pm 41.13$ & \\
\hline Giữa chân & $97.29 \pm 26.07$ & $114.48 \pm 103.08$ & \\
\hline MH1 & $151.46 \pm 75.52$ & $151.12 \pm 49.56$ & \\
\hline MH2 & $220.4 \pm 52.2$ & $221.43 \pm 204.73$ & \\
\hline MH3 & $222.60 \pm 47.15$ & $216.77 \pm 36.1$ & \\
\hline MH4 & $158.21 \pm 32.91$ & $166.43 \pm 37.28$ & \\
\hline MH5 & $133.63 \pm 73.13$ & $140.75 \pm 62.48$ & \\
\hline Ngón cái & $270.33 \pm 133.57$ & $237.29 \pm 139.22$ & \\
\hline Ngón 2 & $121.21 \pm 47.78$ & $143.36 \pm 119.73$ & \\
\hline Ngón 3,4,5 & $85.19 \pm 49.09$ & $96.73 \pm 50.14$ & \\
\hline
\end{tabular}

* MH1: Nền xương ngón 1; MH2: Nền xương ngón 2; MH3: Nền xương ngón 3; MH4: Nền xương ngón 4; MH5: Nền xương ngón 5.

- Áp lực đỉnh bàn chân phải cao hơn bên chân trái không có nghĩa thống kê.

- Sự phân bố áp lực đỉnh giữa các vùng là khác nhau cao nhất là áp lực đỉnh ở vùng ngón cái và thấp nhất là áp lực đỉnh vùng ngón $3,4,5$.

\section{BÀN LUÂN}

Áp lực trung bình bàn chân có thể được tính bằng chia tổng số lực cho toàn bộ diện tích bàn chân. Tuy nhiên trên thực tế thì lực này sẽ phân bố không đồng đều trên toàn bộ diện tích bàn chân nhất là khi đi bộ. Áp lực gan bàn chân là áp lực được tạo ra giữa bàn chân và các bề mặt tiếp xúc trong các hoạt động vận động hàng ngày. Áp lực gan bàn chân phụ thuộc và dáng đi, trọng lượng cơ thể, các bệnh khớp, thần kinh, đái tháo đường...

Nghiên cứu của chúng tôi có chỉ số áp lực đỉnh chung ở chân phải là $334.06 \pm$ $104.83 \mathrm{kpa}$ và chân trái $316.43 \pm 282.14 \mathrm{kpa}$ thấp hơn nghiên cứu của Xiao $\mathrm{HS}$, Yan $\mathrm{L}$ và công sự nghiên cứu năm 2007 trên 1.022 người bình thường sử dụng hệ thống đo áp lực gan bàn chân bằng máy $\mathrm{EMED}$ - $\mathrm{AT}$ ghi nhận kết quả áp lực đỉnh bàn chân bên phải: $427 \pm 128 \mathrm{kpa}$ và chân trái: $428 \pm 116$ kpa do nghiên cứu của chúng tôi có số lượng bệnh nhân thấp hơn; tuổi trung bình thấp hơn và các bệnh nhân tham gia nghiên cứu có chỉ số khối cơ thể của nghiên cứu XiaoHS cao hơn nhiều so với nghiên cứu của chúng tôi.

Năm 2017 Chao Xu, Xin-Xin Wen và cộng sự đo áp lực gan bàn chân của 32 đối tượng tham gia nghiên cứu (17 nam và 15 nữ) sử dụng hệ thống đo Footscan ghi nhận các thông số sau: áp lực đỉnh; thời gian tiếp xúc; diện tích tiếp xúc; tổng thời gian áp lực; áp lực cao nhất và bàn chân được chia làm 10 vùng đo. Với kết quả: Áp lực đỉnh cao nhất ở vùng nền xương ngón $2: 367,5 \pm 87,9 \mathrm{kpa}$; ở 
nền xương ngón 3: 344,6 $\pm 101,4$ kpa; vùng giữa gót chân $255,7 \pm 50,1 \mathrm{kpa}$ và vùng nền xương ngón 4: 234,6 $\pm 56,3$ kpa vùng ngón 2 đến ngón $5: 47,1 \pm 22,3 \mathrm{kpa}$ và vùng bên gót chân 65,3 $\pm 27,3$ kpa [2].

Khi so sánh với nghiên cứu của chúng tôi cho thấy áp lực đỉnh bàn chân cao nhất ghi nhận ở vùng ngón: $222,6 \pm 47,15$ kpa và thấp nhất vùng ngón 3,4,5: 85,19 $\pm 49,09 \mathrm{kpa}$ ở bàn chân phải; ở bàn chân trái cao nhất là vùng ngón cái: $237,29 \pm 139,22 \mathrm{kpa}$, thấp nhất vùng ngón $345: 96,73 \pm 50,14$ kpa. Khi so sánh với nghiên cứu của Chaoxu, Xin Xin chen thấp hơn là do đối tượng nghiên cứu của Chaoxu Xin Xin Chen có độ tuổi trung bình là 26,9 tuổi (thấp nhất 19 tuổi, cao nhất là 36 tuổi) với BMI $22,4 \mathrm{~kg} / \mathrm{m}^{2}$.

\section{KẾT LUẬN}

Áp lực gan bàn chân ở người bình thường phân bố khác nhau ở các vị trí khác nhau trên cùng 1 bàn chân, nhưng không có sự khác nhau giữa 2 bên bàn chân trái và bàn chân phải.

\section{TÀI LIỆ THAM KHẢO}

1. Xiao HS., Yan L., Chen LH., (2007), "sudy of foot plantar pressure in Chinese diabetic patients"

2. Chao Xu., Xin - Xin Wen., el at., (2017), “Normal foot loading parameters andrepeatability of the Footscan ${ }^{\circledR}$ platformsystem" Journal of foot and ankle research, pp 2-10.

3. Veves A., Donaglue M.V., (1998). Pressure assessment methods in the foot

4. Root M., Orien W., Weed J.,(1997). "Normal motion of the foot and leg in gait in: Normal and abnormal function of the foot". Clinical biomechanics, vol 2 pp $128-148$.

5. Maetzler M., BochdanskyT., (2010), "Normal pressure values and repeatability of the Emedt ST2 system", Gait Posture 32: 391.

6. Putti A, B., Arnold G.P., (2010), "Foot pressuredifferences in men and women" foot ankle surg, pp $16-21$. 